\title{
Risk assessment of sexual behaviors in serodiscordant couples
}

\author{
Maria Alexandra Largu*, Carmen Manciuc, Liviu Jany Prisăcariu, Cristina Nicolau, Daniela Stoica, Carmen Dorobăț \\ From The 9th Edition of the Scientific Days of the National Institute for Infectious Diseases Prof Dr Matei Bals \\ Bucharest, Romania. 23-25 October 2013
}

\section{Background}

This paper aims to assess the risk of sexual behaviors in serodiscordant couples in the Infectious Diseases Hospital "Sf Parascheva", Iaşi, Romania.

\section{Methods}

We assessed 40 persons from serodiscordant couples, in the hospital's psycho-social assistance office. Of these, 20 were HIV-positive young men and women registered in the Regional HIV/AIDS Center. Assessments were made between January and August 2013. The instrument used was a questionnaire developed by the psychologist, with questions relating to the frequency of sexual intercourse and contraceptive methods used.

\section{Results}

All the young people we assessed were part of heterosexual couples, with equal numbers of males and females. The average age was 24.76 years, with a minimum of 18 and maximum of 34 years. Participants were mostly postsecondary education or training (31\%), followed in proportion by secondary education (grades $4-8,21 \%$ ), but with a high percentage of high school and university $(20 \%)$ as well. Thirty participants belonged to a family, while 10 were from foster care or placement centers. $46 \%$ of participants were in a relationship based on dating without living together, and equal proportions of $27.5 \%$ were either married or cohabiting. Regarding the duration of the relationship in which they were involved, the majority of participants (51\%) had an ongoing relationship for more than one year, $30 \%$ between 6 months and one year, $15 \%$ between 3 and 6 months and only $3.8 \%$ estimated the duration of their relationship for less than 3 months. Eighty percent declared they have sex once a week or more, $5 \%$ less often than once a week, $10 \%$ said they did

\footnotetext{
* Correspondence: largualexandra@yahoo.com

Infectious Diseases Hospital "Sf Parascheva", Iaşi, Romania
}

not have sex, and the remaining $5 \%$ refused to answer the question. Of the $85 \%$ of sexually active, $29.4 \%$ reported using a condom every time, $58.8 \%$ sometimes and $11.7 \%$ never.

\section{Conclusion}

HIV-positive patients and their HIV-negative partners still assume considerable risk and consciously ignore protection against HIV transmission. However, the results of this study are up for debate due to a certain attitude regarding the disclosure of personal details about one's sex life, still common in the current social context.

Published: 16 December 2013

doi:10.1186/1471-2334-13-S1-P64

Cite this article as: Largu et al:: Risk assessment of sexual behaviors in serodiscordant couples. BMC Infectious Diseases 2013 13(Suppl 1):P64.

Submit your next manuscript to BioMed Central and take full advantage of:

- Convenient online submission

- Thorough peer review

- No space constraints or color figure charges

- Immediate publication on acceptance

- Inclusion in PubMed, CAS, Scopus and Google Scholar

- Research which is freely available for redistribution
C Biomed Central

๑ 2013 Largu et al; licensee BioMed Central Ltd. This is an Open Access article distributed under the terms of the Creative Commons Attribution License (http://creativecommons.org/licenses/by/2.0), which permits unrestricted use, distribution, and reproduction in any medium, provided the original work is properly cited. 